\title{
Playing Poker with Hobbes, Kant and Anderson
}

Victor Asal

vasal@albany.edu

Nina Kollars

nkollars@fandm.edu
Amanda Rosen

amandarosen83@webster.edu

Simon Usherwood

S.Usherwood@surrey.ac.uk

***Draft- please do not cite without permission***

Abstract: There has been previous work that has shown that games based on playing cards can be an effective way of demonstrating to students the logic of Hobbes realist view of the world and the impact of anarchy individually and at the international level in a visceral fashion. This paper builds from this model and develops several approaches that use a similar game format to teach students about different approaches to international relations, specifically realism, liberalism, and constructivism. By changing the rules of the game and allowing for different interactions, students learn to question the deeper theoretical foundations that unify and divide perspectives across the discipline. The paper will specifically address dynamics of liberal institutionalism, collective security and the possible role that identity can play in security choices.

\section{Introduction}

In this paper, we introduce the idea of 'game extensions' as a method of capitalizing on a well-designed game to create more learning opportunities for students. These extensions entail taking a basic game in international relations, and following an initial play, changing the mechanisms, rules, or events in order to explore a new set of theories, concepts, or ideas. This is a particularly valuable technique in international relations, where so many concepts and theories build on and respond to each other. Using a wellknown and widely used game in international relations, we explore this concept of game extensions and the potential benefits it can bring to the IR classroom.

In the remainder of this paper, we will first define game extensions and discuss how they affect student learning through classroom games and simulations. We then re-introduce a specific game that illustrates the benefit of this particular feature of game design, the Hobbes Game first discussed in Asal (2005). A discussion of three possible extensions to the Hobbes game follows. We conclude with some recommendations for creating extensions to other games and some ideas for future research.

\section{Game Extensions in Simulation Design}


A game extension consists of a new or changed mechanic, rule, event, or other alteration to a base game aimed at exposing students to a new idea, theory, concept, or strategy. It is not simply the same game played twice (although repeated play can also have beneficial effects), but instead changes the structure of the previously played game or simulation in order to provoke students into deeper learning. Thus, students will usually play through a base game or simulation once, and then again (either immediately or during another session) with the tweaked game. In some cases, the same base game can be played with multiple extensions, with each new version of the game opening up new opportunities for learning.

If an instructor wishes to use simulations to teach multiple ideas, theories or concepts, there are therefore four options: first, to play a single-concept game multiple times, giving students the opportunity to identify flaws in the logic of the theory. This could result in them organically generating the ideas that serve as a foundation for other theories (Kollars and Rosen 2013). For example, students could play a basic prisoner's dilemma game multiple times, switching anonymous partners each time to prevent iteration from affecting the standard strategy of mutual defection. After multiple plays, they may have more insight into various ways the game could be changed to promote cooperation - thus potentially generating the basic principles of the neo-liberal institutionalist solutions to the prisoner's dilemma prior to being exposed to readings on the subject.

Secondly, we can bring in a multitude of individual games to illustrate different subjects. In this scenario, we would introduce a new game each time we wanted students to actively engage with a particular theory or concept. So instead of replaying the Prisoner's Dilemma game to generate thinking about cooperative solutions in international relations, you might have them play Diplomacy instead, where they are encouraged both to form alliances and to break them.

The third option is to play a complex game that incorporates multiple theories from the outset. This sort of game usually takes place over several class sessions if not the entire term, as there are usually high costs to entry for students in terms of preparation. An example would be Statecraft, an online simulation where teams of students control fictional countries and must make decisions on both domestic and foreign policy while dealing with world issues such as global warming, nuclear weapons, terrorism, and colonialism. Such games may better mimic the complexity of world politics, but run the risk of confusing and frustrating students who find it difficult to juggle the rule system.

The fourth and final method of using simulations to teach multiple ideas and concepts would be to use game extensions, using the framework of a base game and gradually adding in complexity. In this way, extensions create highly portable simulations, allowing for instructors to use the same base game multiple times in the same class (Kollars and Rosen forthcoming). But they also allow for increased portability across courses, as the same base game with different extensions could be used to teach different lessons.

There are two main benefits of using game extensions as opposed to these other options: the reduction in costs for simulation use, and the opportunities for deeper learning. First, game extensions reduce the costs of simulation use. Finding and creating games can entail high cost, particularly in terms of time-instructor time to identify possible games and incorporate them into the class, as well as classroom time spent on students learning the rules of the game so that they can effectively play. When you have students that are 
not used to games - either in their personal lives or in the classroom-it can be difficult to get them into a headspace where they can play the game effectively. Game extensions allow us to minimize the number of times we must ask students to learn new game mechanics, by adding on new rules, mechanics, and gameplay to a previously played game. This can lead to valuable time saved in the classroom.

The second benefit of game extensions is that they can ease students into deeper learning by building complexity over time. The problem with playing individual games-either the same game repeated multiple times, or different games for new lessons played over the course of the term - is that students may end up with a simplistic view of the world we are simulating. In both cases, they see a highly discrete set of rules, and may end up unable to build connections between concepts outside of that rule system. Sacrificing complexity is sometimes necessary in order to help students focus; indeed, the opposite problem - too much complexity — can be just as dangerous. Games like Statecraft, which are complicated from the beginning, mean that the average student may not understand most of the rules and mechanics necessary for effective play until halfway through the game. The rules, in other words, can get in the way of the lesson, particularly for the less experienced gamers amongst our students. While throwing them into a complicated world may be a more accurate simulation of international politics, it does not necessarily lead to better student learning. In another example, if you play a more complex version of the prisoner's dilemma (multiple iterations with the same, known partner, with changing payoff structures in each round), students may end up missing out on the key lesson of the base game, which is that the rational strategy is to defect. Using a base + extensions model minimizes the silo effect of individual games, but also reduces the chances of complexity overwhelming the students.

With these benefits in mind, let us turn to a specific illustration of a base + extensions model. We first re-introduce a commonly used game in international relations, the 'Hobbes' Game, and then discuss three possible extensions to it and the lessons they can teach.

\section{The Hobbes Game}

Since Victor Asal introduced the Classical Realist "Hobbes Game” into the international relations teaching lexicon, it has become a staple of the simulation-friendly international relations classroom. The base game takes only ten minutes to play, requires only a deck of cards, and serves as a ready foundation for the various extensions discussed in the next sections. Students are handed a playing card that represents their game 'life'-lose your card, and you are dead as far as the game is concerned. Cards can be lost through challenges; students are able to challenge each other for their cards and fight duels using rock-paper-scissors. Win, you get all of your opponents' cards. Lose, and you must seek

another life if some are still available from the 'well of souls' (that is, the remaining cards in the deck). Once the Well is closed, students who lose must sit down.

Students are told only that the objective of the game is to survive and that if they are challenged they must fight without negotiation. What newcomers to the game rarely realize is that they are never told that they must challenge anyone, and yet they all readily do so. While a few will figure out that the best way to survive is to hide, feign death, or otherwise avoid being challenged, some students will continue to challenge others even after being told that they are not required to do so. 
The Hobbes game focuses theoretically on human nature. The game is structured so that the students can think about and discuss with evidence (simulated evidence but evidence nonetheless) the nature of humans. They get to wrestle with the challenge that Hobbes makes that we are driven by "... three principal causes of quarrel. First, competition; secondly, diffidence; thirdly, glory (Hobbes 1996 220). More importantly they get empirical evidence that in a situation where everyone (if they all choose) can win, many people choose to fight in order to win- some because they don't realize that multiple winning is possible but some because regardless they want to be the winner. Fundamentally this provides strong ammunition for Hobbes bleak view of human nature:

"[All men have the equality of ability such that the weak may be able to kill the strong] . . . this equality of ability ariseth equality of hope in the attaining of our ends. And therefore if any two men desire the same thing, which nevertheless they cannot both enjoy, they become enemies;”

"During the time men live without a common power to keep them all in awe, they are in a condition which is called war. . . . every man against every man. ... and the life of man [is] solitary, poor, nasty, brutish, and short."

(Hobbes 1996 220).

Thus, this game serves as an excellent introduction to classical realist ideas about international relations. As a base game, it works quite well, particularly as an introductory activity on the first day of class. But there are a number of ways that we can build in new rules and mechanics to extend the game to other ideas and concepts in international relations. We will now look at three such extensions.

\section{Extension I: learning about how to deal with people}

The initial impetus for the Hobbes game was to help students visualize a state of nature, and most of the extensions in this paper suggest developments and modifications thereon. However, it is also possible to approach the game in a slightly different light, as a mechanism for students to start developing their interpersonal and negotiating skills.

This extension is used in a course that focuses on negotiation, using a wide variety of simulations to enable them to gain practice and form a starting point for their reflection. However, because of the very different format of the course, it is helpful to provide students with an introductory exercise that not only flags the participatory nature of the course but also the potential range of issues that they will confront.

In essence, the central learning point is one that relates to the original version of the Hobbes game: namely, that in negotiation it is essential to think not just about yourself, but also about others. This is a fundamental insight of all negotiation models (e.g. Fisher, Ury \& Patton 2011; Breslin \& Rubin 1993) and is consequently a threshold concept in student learning, without which their capacity for development will be sharply limited. Negotiation is intrinsically an interaction between two or more actors, so a failure to consider the interests and situation of the other party is likely to result in poor and/or unsustainable agreements being reached, in the sense that they do not meet all of the parties' needs and that the negotiation might well have damaged the relationship between the parties.

The Hobbes games provides an elegant way into this set of issues. Students are provided with the instructions for the most basic version of the game and left to play it. There then follows a debrief, asking them to explain their choices and actions. In this debrief, part of 
the feedback provided to students is the point outlined above. Even if a student has understood that they can survive simply by not challenging any one (and so risking their demise), the bigger problem comes from those who have not realized this and are happily working their way around the room. Additionally, students will be asked to consider the impact of group dynamics: typically, those who have not been following things too closely will follow the cues of those around them, which tends to contribute to a general move to challenge others. Finally, it is important that there is a discussion about individuals' motivations - whether they challenged or not - since this sets up the next phase of the activity.

This next step consists simply of asking students to play the game once more, with no modifications to the game play. The reasons for doing this are three-fold. Firstly, it gives students an opportunity to reconsider their choices, in light of their prior experience (from the first game) and the debrief. This first cut matters because while most students will switch to a non-challenging mode, not all will: this is discussed below. Secondly, it gives them cause to consider the architecture of the activity itself. This is important in a course with many games and simulations, because they need to have an appreciation of the impact of game design on what they do: all such activities have an element of manipulation, so awareness of, and adaptation to, that manipulation is very important and consequential. Finally, a re-play allows for the provision of more feedback to students, which matters inasmuch as the course is intended to very student-led, so the instructor is actually more of an observer, supporting the reflection process that students begin.

As noted, a second game-play typically results in most students becoming nonchallenging, but not all of them. The ensuing debrief is essential in helping students to understand why there are still defectors from the collective stability of non-challenging. Usually, the reasons given fall into one of three camps: either students have still not understood the learning point (although this is rare), or they like the idea of knocking others out of the game and wish to go out in a blaze of glory or they see that there is no real penalty in challenging and dislike conforming to the group norm. Each of these responses is interesting to discuss, not only for that individual, but for the group as a whole: whatever choice one person has made, they have not made a different choice, and it can often be hard to see why others do not act like yourself. Moreover, given that this group of students will be together for the rest of the semester it is interesting to reflect on how one's actions in this very first game might color peoples' views of you in later exercises (something that is picked up in later sessions).

Something more might be said about the response defecting response, on the lack of sanction. 'Death' in this games actually practically means just sitting down until the game is over. If one wanted to test the depth of this aspect, then one might consider attaching other costs or benefits to the game. Costs might include credit for the course, while benefits might consist of getting everyone to hold real money instead of a playing card. Both options are possible, but need some thought: penalizing students for defecting establishes a norm of compliance that might make some sense in term of classroom behavior, but which makes it much less like the real-world that the exercise is trying to help them prepare for. Likewise, benefits might produce new behavior (greed, or indeed need) that has a place in the discussion, but which cause some difficulty among those who lose, especially it would be as a consequence of others' actions, rather than their own.

This last point leads into another area for discussion, namely how those who do not challenge now react to the potential of being challenged. In more extreme cases, students might remove themselves physically from the room, or pretend to be otherwise engaged, or out of the game. This might be termed aggressive non-challenging and deserves some 
debate, especially since it can take the form of working with someone else to achieve the desired impression, which once again opens up a discussion about cooperative behavior.

While much less complex than the other extensions, the repetition extension creates a simple but effective way to access a number of fundamental aspects of negotiation and negotiation theory, and personal/political behavior more generally.

\section{Extension II: Going Beyond Human Nature}

A second extension of the basic game explores the role of power in realism. Hobbes, after all, only provides one perspective on realism. For Hobbes it is human nature that drives the interactions that lead to making anarchy a constant state of war or preparation for war. What is missing from Hobbes as well as the Hobbes game are other perspectives on realism like Thucydides or Waltz. For Hobbes the key issues are glory, competition and fear- but, there are realist arguments that suggest that power disparities are the key factor that pushes towards violence. In other words, power is only one element in Hobbes equation while for other theorists power and the fear of being the weaker party is THE driving factor. Thucydides for example argues that "The real cause I consider to be the one which was formally most kept out of sight. The growth of the power of Athens, and the alarm which this inspired in Sparta, made war inevitable.” Waltz agrees that the key issue that drives the international system is the distribution of power. The original Hobbes game though provides no basis for the impact of power differentials. Indeed one of its strengths is to highlight that players will attack each other even when there is no benefit in having more cards. As noted above, when the game is played again with the same rules most students (although in a twist that would make Hobbes happy) though not all are much more likely not to fight. This extension which we have labeled the "Hobbes game with power " changes that dynamic and makes capability a factor in the game and thus creates a situation where being stronger (having the right cards) give you power. Does power differentials encourage conflict? This exercise lets the students test this theory themselves. The same logic of victory is used in this game- all who are alive at the end "win". The key twist is that instead of carrying out the duel using dice or playing rock, paper, scissors, the players duel by comparing cards using poker as a model. Specifically:

- A duel is carried out by comparing cards - the highest value card (or set of cards) wins. The challenger can challenge for as many cards as they wish up to the number of cards they have. If they win they can take the number of cards they challenged for. If they lose the defender gets the cards.

- Make the best hand with cards you have at your disposal

- Winning hands

- High card

- A pair

- Three of a kind

- Straight

- Flush

- Full house is

- Four of a kind

- Straight Flush

- Royal Flush 
To realists not surprisingly the results of this rule change are that those with weak hands suggest that the class declare "world peace" while those with strong hands use their cards to attack other players to make even stronger hands. The debriefing can get quite contentious with students accusing other students of being heartless given that they are playing this version knowing that everyone can win. This leads to a discussion of what were effective strategies for survival and for victory as well as how this Hobbes game was (or was not) different than previous Hobbes games. Students often point out that in this game the basis for attacking is "rational" and that since power differentials exist, security "requires" them to amass power by attacking other players. They will tie the arguments directly to Thucydides and Waltz.

\section{Extension III: Learning to Remake the Game-It's All About Structure}

Given the opportunity to play the original or any of the extensions, the students may have noticed that the most simplistic changes in the game create different kinds of outcomes. As game designers know, the introduction of a new rule, incentive, or character will alter the interactions that result. The purpose of this extension is to make the students the game designer and to have them discover the ways in which small shifts in the structure of the game will produce radically different kinds of interactions-including unforeseen ones. This variant can be done either without established resources or with them but students must have played one of the prior games in order to make this activity work.

The premise is straightforward. Ask the students to recall the game, its rules, and the outcomes. Then, ask them to change or add a rule or incentive to the already established game. Rules might include, certain cards afford neutrality status; people holding King cards can call on other players to help them defend themselves; anything is possible. Be certain, however, to ensure that students select only a few small adjustments rather than many wholesale changes. This makes it easier for students to determine the outcomes and effects that have shifted in the process. The same debriefing process used in other versions applies here as well: What did we observe happening? Does this interaction seem to mimic something we see in international relations, or is it rather something we would hope to see in the future? Does anyone have any real world examples of when this might actually have occurred?

The second approach is even more analytical and can be used to draw out more finegrained aspects of a particular author's view of global anarchy. The instructor begins by asking the students to read a journal article that features an institutional solution to the problem of anarchy. Of particular interest in my course is the Kupchan and Kupchan piece on collective security. After discussing their view of what institutions bring to softening the security dilemma, ask the students to introduce a rule into the Hobbes game that mimics the dynamic that the Kupchan's suggest will resolve some of the issues. By asking students to search for the implied mechanism in the reading and to create a corresponding rule within the game, students are actively engaging the deeper points and testing their ability to transfer those ideas into their own game.

The shortcoming of this exercise, is of course, its mechanistic nature. It risks drawing students into an overly structure-based and hyper-rational view of international interaction. As a result it is important in any debrief to discuss the many outliers and competing interpretations of the game that exist in order to avoid creating IR thinkers that are bound to purely game theoretic explanations.

\section{Conclusions}


These are just three of the possible extensions to the Hobbes Game. There are still others, such as the Alliances extension, which uses the poker rules of Extension II but allows students to trade and share cards as well as wage war for them, or the Ethnic Conflict extension, where students get bonus points added to their score for every student who shares their favorite musician or band. In the first extension, students find teaming up to be a very effective strategy as it can be used either for offense (to take the cards of weaker teams) or defense (to deter challenges), but they can also be burned by their allies, as any cards shared with another player may not ever be returned. In the second extension, some students will find themselves changing their favorite musician when they find out they are in a minority, while others will refuse to change their allegiance (usually Grateful Dead fans)_-illustrating how some people will try to assimilate into a conquering culture and others will refuse to do so.

These extensions are by no means the only ways of adapting the Hobbes game. Likewise, the Hobbes game is not the only one ripe for extensions. Other staples of the IR game canon, such as Diplomacy and the Prisoner's Dilemma, also benefit from extensions. Diplomacy, for example, can be changed into 'Nuclear Diplomacy' where players get access to nuclear weapons and see the potential impact of mutually assured destruction. Likewise, while playing a single shot prisoners' dilemma game illustrates realist ideas about cooperation, repeated play with varying payoff structures and players (for example, having pairs of friends be prisoners rather than a random, unknown person in the class) allows students to see the neo-liberal institutionalist solutions to engendering cooperation within the prisoner's dilemma.

The key take-home point of this piece, therefore, is that building extensions onto games allows us to take advantage of the time invested in teaching students the rules of one game in order to teach them new ideas, concepts, and lessons about international relations. Moreover, by using the same game structure, it can help students see how these concepts overlap and intersect, as opposed to the silo view that might take hold if each concept or theory is the subject of a unique game. 


\section{Bibliography}

Asal, V. 2005. Playing Games with International Relations. International Studies Perspectives 6: 359-373.

Asal, Victor, Steve S. Sinb, Nolan P. Fahrenkopfc, and Xiaoye Shed. "The Comparative Politics Game Show: Using Games to Teach Comparative Politics Theories." In MPSA, 20. Chicago, Illinois, 2012.

Breslin, John William, and Jeffrey Z. Rubin, eds. Negotiation theory and practice. Program on Negotiation, 1993.

Fisher, Roger, William L. Ury, and Bruce Patton. Getting to yes: Negotiating agreement without giving in. Penguin, 2011.

Hobbes, Thomas " OF THE NATURAL CONDITION OF MANKIND AS CONCERNING THEIR FELICITY AND MISERY," in Vasquez, John ed. (1996) Classics of International Relations New Jersey: Prentice Hall Inc.

Kollars, Nina, and Amanda M. Rosen. "Simulations as Active Assessment? Typologizing by Purpose and Source.” Journal of Political Science Education 9 (2013): 144-156.

Kollars, Nina, and Amanda M. Rosen. "Portability and Bootstrapping in Simulation Design.” International Studies Perspectives, forthcoming.

Kupchan, Charles A., and Clifford A. Kupchan. "The Promise of Collective Security." International Security 20, no. 1 (1995): 52. 